\title{
African CO emissions between years 2000 and 2006 as estimated from MOPITT observations
}

\author{
F. Chevallier, A. Fortems, P. Bousquet, I. Pison, S. Szopa, M. Devaux, and D. A. Hauglustaine \\ Laboratoire des Sciences du Climat et de l'Environnement/IPSL, CEA-CNRS-UVSQ, Gif-sur-Yvette, France
}

Received: 24 June 2008 - Published in Biogeosciences Discuss.: 18 September 2008

Revised: 17 December 2008 - Accepted: 17 December 2008 - Published: 16 January 2009

\begin{abstract}
The space-time variations of the carbon budget at the Earth's surface are highly variable and quantifying them represents a major scientific challenge. One strategy consists in inferring the carbon surface fluxes from the atmospheric concentrations. An inversion scheme for the hydrocarbon oxidation chain, that includes $\mathrm{CO}$ and $\mathrm{CH}_{4}$, is presented here with a focus on the African continent. It is based on a variational principle. The multi-tracer system has been built as an extension of a system initially developed for $\mathrm{CO}_{2}$ and includes a new simplified non-linear chemistry module. Individual in situ measurements of methyl-chloroform and individual retrievals of $\mathrm{CO}$ concentrations from the Measurements Of Pollution In The Troposphere (MOPITT) spaceborn instrument have been processed by the new system for the period 2000-2006 to infer the time series of CO emissions at the resolution of $2.5^{\circ} \times 3.75^{\circ}$ (latitude, longitude). It is shown that the analysed concentrations improve the fit to five independent surface measurement stations located in or near Africa by up to $28 \%$ compared to standard inventories, which confirms that significant information about $\mathrm{CO}$ emissions can be obtained from MOPITT data. In practice, the inversion reduces the amplitude and the interannual variability of the seasonal cycle in the northern part of Africa, with a longer burning season. In the southern part, the inversion mainly shifts the emission peak by one month later in the season, consistent with previously-published inversion results.
\end{abstract}

\section{Introduction}

The prevailing climatic and economic conditions in Africa have hampered the observation of its carbon budget by conventional networks so far. The lack of measurements in turn

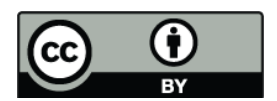

Correspondence to: $\mathrm{F}$. Chevallier (frederic.chevallier@1sce.ipsl.fr) makes the numerical models of the carbon cycle, mostly their soil and vegetation components, highly uncertain when applied to Africa since the models are usually developed and validated for different latitudes. Direct (i.e. concentrations of carbon compounds, Turner, 1993) and indirect (i.e. vegetation activity, Tucker, 1979) observations of the carbon cycle have been made from space for several decades. The retrievals of carbon compound concentrations (e.g., Deeter et al., 2003; Chédin et al., 2003) have poor vertical resolution and much higher uncertainties than surface measurements, but they circumvent the local constraints and provide large densities of data. Further, they are particularly suited for Africa because biomass burning is both a prominent component of the carbon budget there (Ciais et al., 2008) and a major signal in the satellite radiances. The exploitation of these remotely-sensed concentrations in terms of carbon surface budget (for $\mathrm{CO}_{2}, \mathrm{CO}$ and $\mathrm{CH}_{4}$ ) has started only recently but the inversion systems are rapidly gaining in sophistication (Arellano et al., 2004; Pétron et al., 2004; Chevallier et al., 2005; Bergamaschi et al., 2007).

The present study focuses on the African CO budget over a seven-year period (2000-2006) by combining several sources of information within a Bayesian inversion system. The first information sources, which we will call here "a priori", are mainly version 2 of the Global Fire and Emission Database (GFEDv2) developed by Van der Werf et al. (2006) combined with the Emission Database for Global Atmospheric Research (EDGARv3) fossil fuel inventory of Olivier and Berdowski (2001). EDGARv3 is a based on international statistics and GFEDv2 is a high-level product with contributions from different space-born observations of fires and of vegetation and from a numerical model of the terrestrial vegetation. The second information source, which we call "observations" in the inversion system, is the dataset of the $\mathrm{CO}$ concentrations retrieved from the MOPITT instrument (Deeter et al., 2003) that has been flying onboard NASA's EOS Terra satellite since the end of

Published by Copernicus Publications on behalf of the European Geosciences Union. 
1999. The inversion system gathers three other information types: methyl-chloroform (MCF) surface measurements to constrain the concentrations of the hydroxyl radical $\mathrm{OH}$, a global chemistry-transport model and the error statistics associated to each information piece. The code follows the Bayesian variational framework initiated by Chevallier et al. (2005) for $\mathrm{CO}_{2}$. The method and the data are detailed in the next section. Section 3 presents the results and the last section concludes the study.

\section{Data and method}

\subsection{Chemistry-transport model}

Carbon monoxide is produced from the combustion of fossil fuels and biomass, and from the oxidation of hydrocarbons. Its chemical consumption by the $\mathrm{OH}$ radical makes its average lifetime in the atmosphere about one month in the Tropics (Mauzerall et al., 1998). Consequently CO is subjected to long range transport. A new chemistry-transport model has been developed to interpret the concentration measurements in terms of surface emissions. The model has been conceived as a simplification of LMDZ-INCA: LMDZ refers here to version 4 of the general circulation model of the Laboratoire de Météorologie Dynamique (Hourdin et al., 2007) and INCA stands for Interaction with Chemistry and Aerosols (Hauglustaine et al., 2004; Folberth et al., 2006). We will refer to the simplified model as LMDZ-Simplified Atmospheric Chemistry System (LMDZ-SACS). It is run here at horizontal resolution $3.75^{\circ} \times 2.5^{\circ}$ (longitude-latitude) and with 19 vertical levels between the surface and the midstratosphere $(\sim 30 \mathrm{~km})$.

The simplifications of LMDZ-SACS compared to LMDZINCA have been introduced to minimize the computational burden in the context of a variational (iterative) inversion system. For the transport part, the simplification consists in using a frozen archive of 3-hourly transport mass fluxes rather than running the full general circulation model LMDZ (Hourdin et al., 2006). The archive has been obtained from a previous simulation of LMDZ for the same dates, guided by the horizontal winds analysed by the European center for Medium-Range Weather Forecasts (ECMWF). The simplification for the chemistry consists in explicitly solving the main reactions of a limited set of four species only: $\mathrm{CH}_{4}$, $\mathrm{CO}$, formaldehyde $(\mathrm{HCHO})$ and $\mathrm{MCF}$. The reactions considered are:

- the oxidation of $\mathrm{CH}_{4}$ by $\mathrm{OH}$, with $\mathrm{HCHO}$ as a product,

- the oxidation of $\mathrm{HCHO}$ by $\mathrm{OH}$, with $\mathrm{CO}$ as a product,

- the oxidation of $\mathrm{CO}$ by $\mathrm{OH}$,

- the oxidation of MCF by $\mathrm{OH}$,
- the reaction between $\mathrm{CH}_{4}$ and excited atomic oxygen $\left(\mathrm{O}^{1 \mathrm{D}}\right)$,

- the photolysis of HCHO.

Intermediate reactions are considered as very fast compared to the reactions above. Their yields are pre-computed using the full LMDZ-INCA that considers the $\mathrm{NMHC} / \mathrm{CH}_{4} /$ $\mathrm{O}_{\mathrm{x}} / \mathrm{NO}_{\mathrm{x}}$ chemistry as described in Folberth et al. (2006). The surface emissions of $\mathrm{CH}_{4}, \mathrm{CO}, \mathrm{HCHO}$ and MCF are included in LMDZ-SACS. Biomass burning emissions are emitted at the surface in the model since fire emissions are usually not directly injected in the free troposphere (Labonne et al., 2007). An additional source of $\mathrm{HCHO}$ arises from the degradation of volatile organic compounds (VOC) and is prescribed in the simplified model based on a previous simulation with the full LMDZ-INCA model. OH concentrations and constants of reactions are prescribed in the same way. Comparisons between LMDZ-SACS and LMDZ-INCA indicate that the simplified model differs from the reference by less than $15 \%$ for $\mathrm{CO}$ individual concentrations with negligible bias (Pison et al., 2008).

The adjoint code of LMDZ-SACS has been developed for an efficient minimization of the cost function $J$ described in the next section.

\subsection{Inversion scheme}

The inversion system described by Chevallier et al. (2005, 2007) aims at optimizing a series of variables gathered in a state vector $\boldsymbol{x}$, based on some observations $\boldsymbol{y}$ and on some prior guess $\boldsymbol{x}_{\boldsymbol{b}}$. The merging of information exploits the error statistics of each information source, assumed to be Gaussian-distributed and unbiased, within a Bayesian methodology. Technically, the optimal solution (in a statistical sense) is found by iteratively minimizing the following cost function:

$$
\begin{aligned}
& J(x)=\left(x-x_{b}\right)^{T} \mathbf{B}^{-1}\left(x-x_{b}\right) \\
& +(H(x)-y)^{T} \mathbf{R}^{-1}(H(x)-y)
\end{aligned}
$$

$\mathbf{B}$ and $\mathbf{R}$ are the error covariance matrices of the prior and of the observations, respectively. $H$ is the operator that computes the equivalent of $\boldsymbol{y}$ from $\boldsymbol{x}$, i.e. the combination of LMDZ-SACS and of the MOPITT averaging kernels. This strategy follows the data assimilation systems that the numerical weather prediction community has been developing for several decades (Le Dimet and Talagrand, 1986).

Consistent with LMDZ-SACS, the vector $\boldsymbol{x}$ is made of:

- global 2-D maps of CO emissions at an 8-day and $3.75^{\circ} \times 2.5^{\circ}$ (longitude-latitude) resolution over a chosen period of time (here 13 months at a time),

- global 2-D maps of $\mathrm{CH}_{4}$ emissions at the same resolution, 
- global 2-D maps of factors, at the same resolution, to scale at once the surface emissions of $\mathrm{HCHO}$ and its 3-D atmospheric production by VOC,

- scaling factors for the 4-D OH concentrations fields every 8 days for four latitude bands $(90 \mathrm{~S}-30 \mathrm{~S}, 30 \mathrm{~S}-0$, $0-30 \mathrm{~N}, 30 \mathrm{~N}-90 \mathrm{~N})$. Note that more regions could be introduced if there were more stations (Bousquet et al., 2005),

- global 2-D maps of factors, at $3.75^{\circ} \times 2.5^{\circ}$ resolution, that scale the 3-D concentrations of $\mathrm{CO}, \mathrm{CH}_{4}$ and $\mathrm{HCHO}$ at the initial time step of the inversion window.

The eight-day temporal resolution of the state vector materializes the idea that the prior information likely has large temporal error correlations at the scale of days and small error correlations at the scale of weeks. This subjective guess has been confirmed for $\mathrm{CO}_{2}$ fluxes by Chevallier et al. (2006) and similar studies should be conducted in the future for the species considered here. Emissions within any of the eightday periods are interpolated in time from the state vector $\mathbf{x}$ to a 30-min resolution before being transported in LMDZSACS.

The observations $\boldsymbol{y}$ are the individual MCF measurements and the MOPITT retrievals of $\mathrm{CO}$, sampled per orbit at the $3.75^{\circ} \times 2.5^{\circ}$ model resolution. The processed datasets cover the globe, and the results outside of Africa will be presented in a future paper rather than in this special issue.

The presence of $\mathrm{OH}$ among the optimized variables makes the $H$ operator diverge from linearity and makes the cost function $J$ diverge from quadraticity. In this context, our minimisation strategy relies here on the M1QN3 limited memory quasi-Newton software (Gilbert and Lemaréchal, 1989) applied to the classical preconditioned variable $z=\mathbf{B}^{-1 / 2}\left(\boldsymbol{x}-\boldsymbol{x}_{\boldsymbol{b}}\right)$.

For technical reasons, the seven-year period considered here is processed in consecutive 13-month chunks with a 1month overlap from one chunk to the next. The overlap was found large enough not to introduce significant artificial discontinuity. Each chunk involves about 950000 observations and 1870000 variables to optimize. The four chemical tracers are processed together consistently with the simplified chemistry. Five iterations are performed that reduce the norm of the gradient of $J$ with respect to the control variables by about $95 \%$. With twice as less observations as variables to infer, the inversion problem is clearly underconstrained: the prior guess $\mathbf{x}_{\mathbf{b}}$ regularizes it.

The Bayesian theory provides the errors of the optimal solution to the inversion problem (e.g., Rodgers, 2000). Such a theoretical estimation is an interesting diagnostic, but poses numerical problems when both the state vector and the observation vector are large. The Monte Carlo method of Chevallier et al. (2007) is used here for this computation. We recall its successive steps:
- run the LMDZ-SACS chemistry-transport model with a climatology of surface emissions to generate a set of pseudo MOPITT and MCF observations at the same location and time as the actual measurements,

- perturb the pseudo-observations consistently with assumed observation error statistics (described later in the section),

- perturb the state vector (that includes the surface flux climatology) consistently with assumed error statistics (described later in the section),

- perform a Bayesian inversion of the surface fluxes using the perturbed pseudo-observations as data and the state vector as the prior field,

- compare the estimate of the inversion to the flux climatology to get the errors in the estimate.

The method is applied several times with different perturbations each time, in order to compute the posterior error statistics. When using a statistical ensemble of increasing size, the method converges towards the usual Bayesian theoretical formula. In the present study, an ensemble of two oneyear global inversions of eight-day surface fluxes is used.

\subsection{Satellite CO retrievals}

The MOPITT instrument has been operated since March 2000 on the polar-orbiting sun-synchronous Terra platform, which crosses the equator at 1030 and 2230 local time approximately. Two to three days worth of MOPITT radiances offer a near global coverage with a $22 \times 22 \mathrm{~km}^{2}$ horizontal resolution for the nadir fields of view. The official MOPITT CO concentration product (level 2 version 3) is available in the form of profiles of mixing ratios at seven nominal levels between the surface and $150 \mathrm{hPa}$ (Deeter et al., 2003). The retrieval algorithm is based on optimal estimation, like our emission inversion system. It evolved between Phase 1 (March 2000-May 2001) and Phase 2 (from August 2001) of the MOPITT operations due to the failure of four channels since May 2001 (Emmons et al., 2004). An averaging kernel is associated to each profile. It describes how the measurements and the prior concentration profile influence the retrieval at each level and estimates the retrieval uncertainty. Since the retrieval is based on measurements in the thermal infrared spectral range, the actual vertical resolution of a retrieved profile depends on the thermal contrast between the surface and the atmosphere and on the thermal gradients within the troposphere. Even in the most favourable observation conditions, the measurements provide less than two pieces of information in the vertical with larger information content for tropical daytime scenes (Deeter et al., 2004): the upper levels in the retrieved CO profile are primarily sensitive to upper tropospheric $\mathrm{CO}$ and 


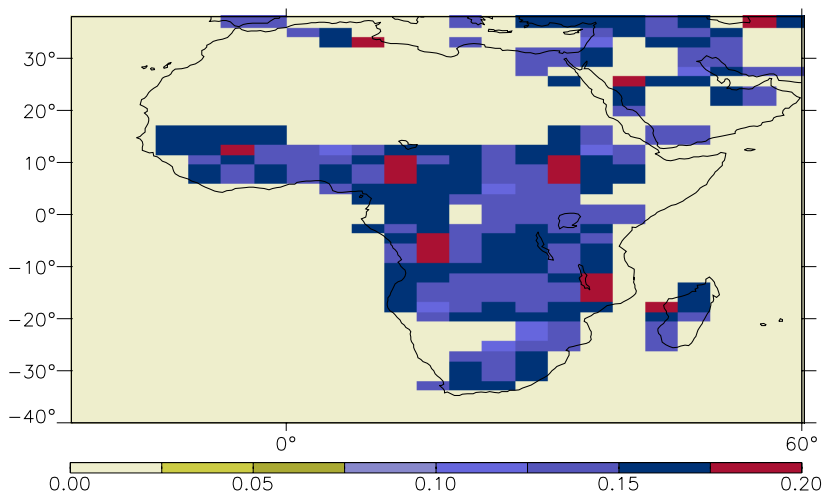

Fig. 1. Prior error standard deviations, in $\mathrm{g} \cdot \mathrm{m}^{-2}$ per day, for the eight-day mean grid point CO surface emissions in 2004.

the lower levels in the retrieved profile are primarily sensitive to CO between 300 and 800 mbar (Deeter et al., 2003). As a compromise between data volume, closeness to the surface and retrieval noise, only the $700 \mathrm{hPa}$-level retrievals, together with their respective averaging kernels, are used here. Following the recommendations associated with the product (http://web.eos.ucar.edu/mopitt/data/, access: 28 May 2008), data within $25^{\circ}$ from the poles, or corresponding to nighttime, or for which the so-called "prior contribution" exceeds $50 \%$ have been left out. The data have then been sampled at the resolution of the chemistry-transport model to avoid possibly large correlations for measurement and model errors within a model grid box. This screening keeps between 2500 and 5000 MOPITT spots per day in the inversion system, to be compared with the $69003.75^{\circ} \times 2.5^{\circ}$ boxes of the LMDZ-SACS global horizontal grid.

The inversion system does not distinguish between the representativeness errors, the errors of the observation operator and the measurement errors. The MOPITT official product includes an estimation of the measurement random error for each individual retrieval. It is about $10 \%$ standard deviation for each retrieval, with regional biases of a few parts per billion (ppb) (Emmons et al., 2004). The errors of the observation operator (i.e. LMDZ-SACS) and those of representativeness (i.e. the mismatch between observation and model resolutions) are difficult to quantify. LMDZ-SACS accumulates the errors of the reference model LMDZ-INCA (which are bounded but not quantified) and those of the simplifications (about $15 \%$ as mentioned in Sect. 2.1). As a consequence, we arbitrarily defined the variance of the individual observation errors in $\mathbf{R}$ by summing the square of the MOPITT error standard deviations with the variance corresponding to $50 \%$ of the measured values (to account for representativeness random errors, model random errors and likely measurement and model biases). Error correlations between different observations were ignored. Doing so, the free chemistry-transport model already fits the observations within their assigned uncertainty. The minimization further improves the fit. MOPITT biases are neglected even though there is evidence of some systematic errors in the products (Emmons et al., 2008).

\subsection{MCF measurements}

$\mathrm{CO}$ is the main species reacting with $\mathrm{OH}$ in the troposphere: $\mathrm{OH}$ affects both its atmospheric production and its removal. Therefore $\mathrm{OH}$ is a key component for the analysis of $\mathrm{CO}$ concentrations. However, its high reactivity (inducing a very short lifetime) prevents observations of $\mathrm{OH}$ with a sufficient spatio-temporal representativity to deduce its global climatology. Several authors have used MCF measurements to infer $\mathrm{OH}$ fields because MCF has rather well known sources and interacts only with $\mathrm{OH}$ (e.g., Prinn et al., 1995; Bousquet et al., 2005). The present study innovates because it exploits MCF in synergy with other reactive species rather than as a separate preliminary step: $\mathrm{CO}$ concentrations complement $\mathrm{MCF}$ to infer the $\mathrm{OH}$ concentrations and inferred $\mathrm{CO}$ emissions benefit from the full statistical information about MCF without any filter.

A series of 12 stations measuring $\mathrm{MCF}\left(\mathrm{CH}_{3} \mathrm{CCl}_{3}\right)$ nearly continuously for the 2000-2005 period has been selected from the ALE/GAGE/AGAGE and NOAA/ESRL networks (e.g., Prinn et al., 2000; Montzka et al., 2000). The stations are: Alert (Canada), Barrow (US-AK), Cape Grim (Australia), Cape Kumukahi (US-HI), Park Falls (US-WI), Cape Matalula (American Samoa), Mace Head (Ireland), Mauna Loa (US-HI), Niwot Ridge (USA-CO), Palmer Station (Antartica), Ragged Point (Barabados), South Pole. Errors are defined at each station from Bousquet et al. (2005) and range between 1 and 2 ppt (parts per trillion).

\subsection{Prior emissions}

Prior CO emissions are taken from standard databases for biomass burning (GFEDv2, Van der Werf et al. (2006), http://www.geo.vu.nl/ gwerf/GFED/data/) and fossil fuel (EDGARv3, Olivier and Berdowski (2001)). Prior emissions for the other species, like non-methane volatile organic compounds, or from biogenic origin follow the inventory gathered for the full chemistry-transport model LMDZ-INCA (Folberth et al., 2006).

Considering the large uncertainties that still affect such emission inventories (e.g., Boschetti et al., 2004; Van der Werf et al., 2006), standard deviations of the eight-day prior emission errors are arbitrarily set to $100 \%$ of the maximum value of the emission time series during the year for each grid point, except for MCF where it is set to $1 \%$ as its emissions are supposed to be better known than for $\mathrm{CO}$ (Bousquet et al., 2005). Figure 1 displays the map of CO prior error standard deviations over Africa for year 2004 as an example, with negligible values over the deserts and the oceans and large ones over biomass-burning areas. The prior scale factors are 
Table 1. Estimates of the annual budget of $\mathrm{CO}$ emissions, in $\mathrm{Tg}$ of $\mathrm{CO}$ per year, for the two African regions, in the prior and in the posterior inventories. The top row corresponds to Phase 1 of the MOPITT instrument.

\begin{tabular}{lrrrr}
\hline Year & $\begin{array}{r}\text { Prior } \\
\text { NHA }\end{array}$ & $\begin{array}{r}\text { Posterior } \\
\text { NHA }\end{array}$ & $\begin{array}{r}\text { Prior } \\
\text { SHA }\end{array}$ & $\begin{array}{r}\text { Posterior } \\
\text { SHA }\end{array}$ \\
\hline $\begin{array}{l}\text { April 2000- } \\
\text { March 2001 }\end{array}$ & 177 & 173 & 96 & 136 \\
2002 & 151 & 152 & 96 & 114 \\
2003 & 137 & 136 & 98 & 123 \\
2004 & 142 & 144 & 95 & 111 \\
2005 & 149 & 151 & 105 & 132 \\
2006 & 135 & 149 & 90 & 116 \\
\hline
\end{tabular}

set to 1 with arbitrary error standard deviations of $100 \%$ and $10 \%$ for $\mathrm{HCHO}$ and $\mathrm{OH}$, respectively. The correlations of the prior errors have been assigned for all variables following what had been done for $\mathrm{CO}_{2}$ by Chevallier et al. (2007): temporal correlations are neglected and spatial correlation are defined by a relatively short e-folding length $(500 \mathrm{~km})$ over land and a larger one $(1000 \mathrm{~km})$ over the ocean.

The uncertainty about emissions, when aggregated at the scale of regions and months, results both from the grid-point error standard deviation and from the assigned spatial correlations. For instance, in 2004, the assigned uncertainty amounts to about $45 \mathrm{Tg}$ of $\mathrm{CO}$ per year for Northern Hemisphere Africa (NHA) and to about $32 \mathrm{Tg}$ for Southern Hemisphere Africa (SHA).

\section{Results}

\subsection{Expected uncertainty reduction}

As a preliminary step, the impact of the MOPITT data on the estimation of the $\mathrm{CO}$ fluxes is quantified using the Monte Carlo method described Sect. 2.2 and applied to the data of 2004. The map of the error reduction is shown in Fig. 2. As expected from a Bayesian system with rather uniform data coverage (Chevallier et al., 2007), the map is very similar to that of the prior error standard deviations shown in Fig. 1. In biomass burning areas the values are about 20\%, reaching up to $45 \%$ for some grid points. By construction, those figures are yearly averages and should be larger in biomass burning seasons. Estimating the seasonal cycle of the error reduction would require a larger statistical ensemble of inversions.

The aggregated posterior random uncertainty for year 2004 amounts to about $38 \mathrm{Tg}$ of $\mathrm{CO}$ for NHA and $28 \mathrm{Tg}$ for SHA. The uncertainty reduction reaches about $20 \%$ for NHA and $10 \%$ for SHA. These figures should be taken with caution since the prior errors have been assigned rather arbitrarily. Further, some systematic errors are known to affect the MOPITT products (Emmons et al., 2008) and could also bias the inversion estimate.

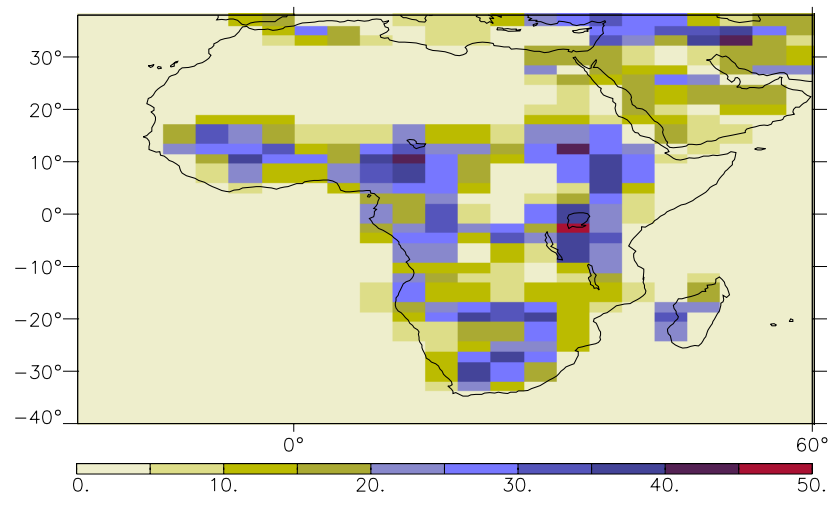

Fig. 2. Error reduction, in $\%$, of the eight-day mean grid point $\mathrm{CO}$ surface emissions. The error reduction is defined as (1$\left.\sigma_{a} / \sigma_{b}\right) \times 100$, with $\sigma_{b}$ the prior error standard deviation shown in Fig. 1 and $\sigma_{a}$ the posterior error standard deviation.

\subsection{Concentrations and emissions}

Figure 3 illustrates the behaviour of the inversion system with some results for the month of July 2003. The MOPITT mean concentrations and the concentrations before and after the inversion are displayed. By construction, the inversion brings the concentrations closer to the observations than the prior, with mean increments of up to $25 \%$ of the prior concentrations. The values in NHA and South of $20 \mathrm{~S}$ are increased, while those between the Equator and $20 \mathrm{~S}$, associated to biomass burning in this season, are decreased. The model does not exactly fit the observations for three reasons. First, the finite prior uncertainty on the emissions pulls the posterior toward the prior values. Second, the chemistrytransport model is used as a hard constraint in the inversion and therefore smoothes out the space-time variations of the concentration fields. Third, the assigned observations errors are large.

Figure 4 presents the results for $\mathrm{CO}$ concentrations and emissions over the seven year period and for the two African regions. The series mainly reflect the seasonal cycle of biomass burning with maximum values in boreal winter for NHA and late austral winter in SHA. The inversion appears to smooth out the concentration time series in the North, with a longer burning season and a smaller interannual variability. In the South, the inversion mainly shifts the emission peak by one month later in the season. The Southern emissions are still smaller than the Northern ones on an average. The annual budgets are given in Table 1 . Note that some drift in the MOPITT product errors may affect the interannual variations of the inverted emissions (Emmons et al., 2008).

We performed a series of sensitivity studies to evaluate the robustness of the inverted fluxes by varying the $\mathrm{OH}$ assigned prior errors (from 10 to $35 \%$ ), by varying the $\mathrm{OH}$ prior field (the alternate prior field had been obtained from a simulation 
(a) MOPITT

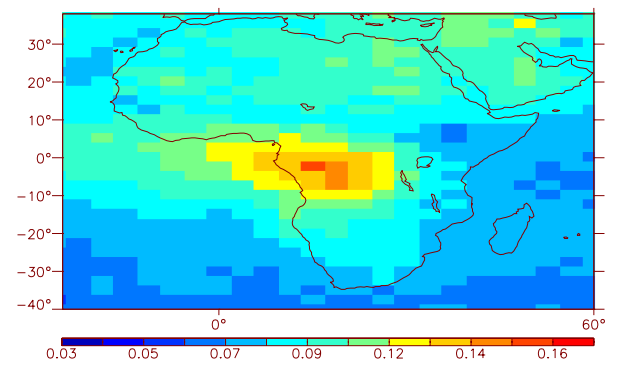

(c) Posterior

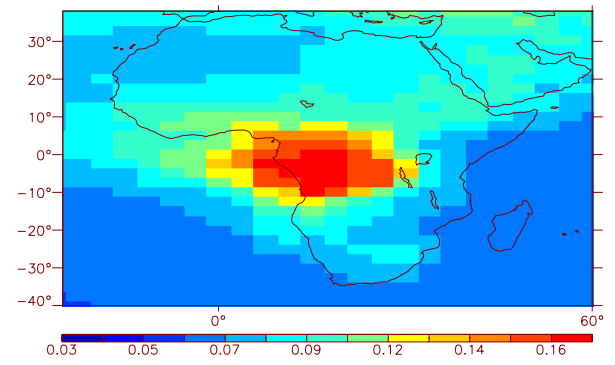

(b) Prior

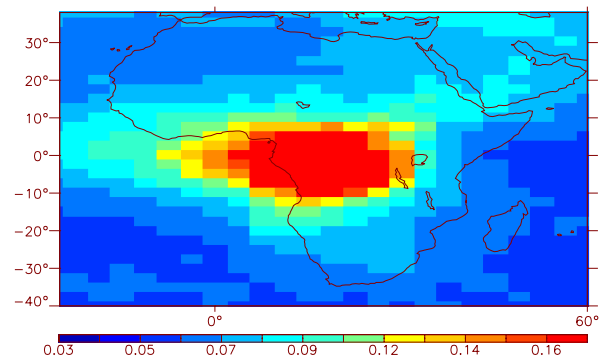

Fig. 3. Mean CO concentrations, in parts per million, for July 2003 in (a) the MOPITT observations for the $700 \mathrm{hPa}$ pressure level, (b) the prior simulation and (c) the posterior simulation. The simulations take the individual MOPITT averaging kernels into account. Abscissa and ordinate report the longitudes and latitudes.
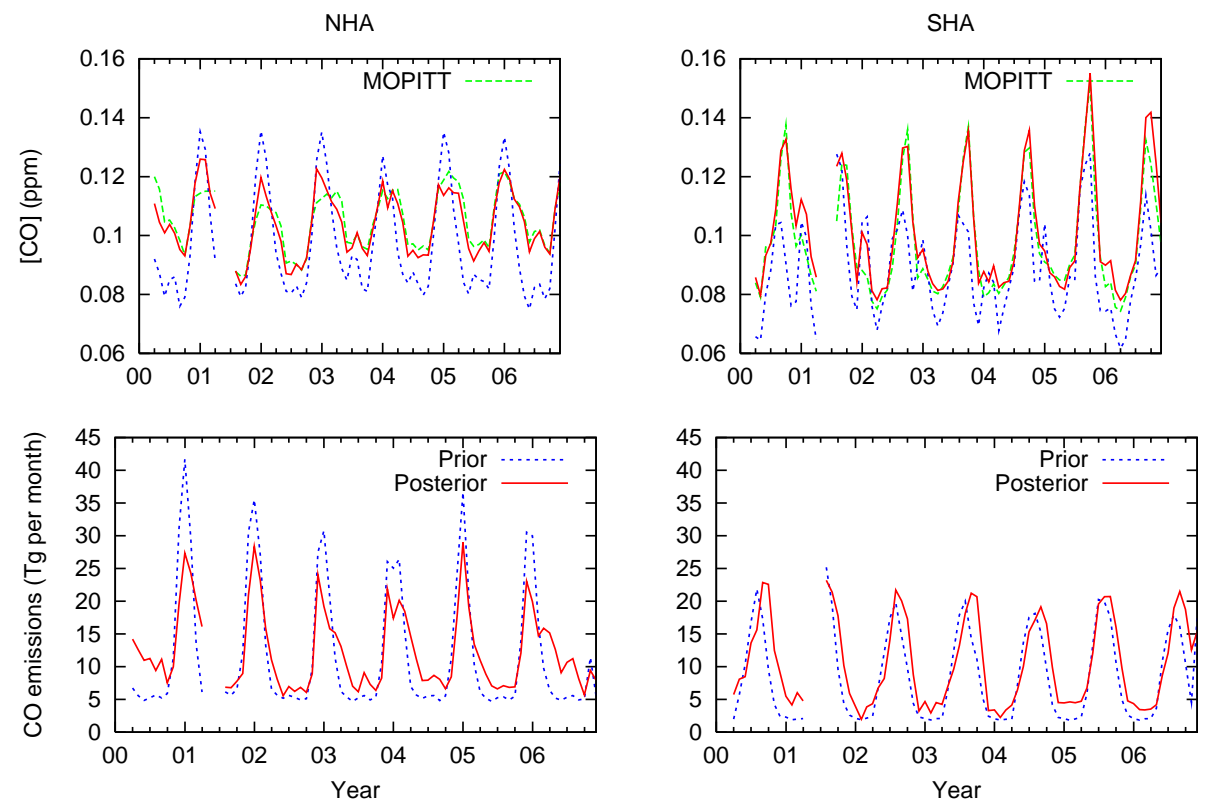

Fig. 4. Time series of the $\mathrm{CO}$ concentrations (top row, for the 700hPa level with corresponding MOPITT averaging kernels) and of the CO emissions (bottom row) for regions NHA (left column) and SHA (right column) in the prior simulation (blue curve) and in the posterior simulation (red curve). CO concentrations from MOPITT (in green) are reported in the concentration figures (top row). The values reported in both rows are monthly averages.

of LMDZ-INCA with different emission inventories), by removing the MCF observations, by varying the $\mathrm{CO}$ assigned prior errors (from 50 to $400 \%$ of the annual maximum emis- sion value), by switching to release number 3 of LMDZ (we use version 4 here) and by adding offsets to MOPITT data (the offsets amount to a few ppb). In contrast to other parts 
of the globe (not shown here), the results over Africa appear to be very robust. The range of inverted fluxes is about $15 \%$ of the inverted emissions only (it is $24 \mathrm{Tg}$ for NHA and $17 \mathrm{Tg}$ for SHA), i.e. well within the theoretical posterior uncertainty of section 3.1. Among the tests that we performed, varying the $\mathrm{OH}$ assigned prior errors from 10 to $35 \%$ had the largest impact. The two main inversion features (i.e. smoother series in the North and a shifted burning season in the South) were already noted by Pétron et al. (2004) and by Arellano et al. (2006) who independently processed the April 2000-March 2001 MOPITT data with different inversion systems.

The multi-tracer chemistry LMDZ-SACS couples the species. As a consequence, the $\mathrm{CO}$ observations induce increments for all species. HCHO increments over Africa are about a few per cent. Their geographical distribution is similar to the CO increments (not shown), which may indicate that the system is not able to separate the atmospheric production of $\mathrm{CO}$ from its surface emissions. In other words, errors in the atmospheric production may alter the inversion increments. However, the atmospheric production in LMDZSACS amounts to about $10 \mathrm{Tg}$ per month in NHA and to about $5 \mathrm{Tg}$ per month in SHA, which is already smaller than the emission values during the fire seasons (Fig. 4). The errors in the modeled atmospheric production are expected to be even smaller. $\mathrm{CH}_{4}$ increments are negligible. $\mathrm{OH}$ is mainly constrained by MCF in our system. Its spatial distribution is hardly affected, but the amplitude of the seasonal cycle is reduced by about $2 \%$. The phase of the seasonal cycle remains unchanged.

\subsection{Fit to independent surface measurements}

In order to validate the inversion, the posterior concentrations have been compared to independent surface flask measurements from the NOAA ESRL measurement network for the 2000-2006 period. We used five measurements stations located in the African continent or nearby: ASC (Ascension Island, 7.92 S, $14.42 \mathrm{~W}$ ), ASK (Assekrem, Algeria, $23.18 \mathrm{~N}$, 5.42 E), IZO (Tenerife, Canary Islands, $28.30 \mathrm{~N}, 16.48 \mathrm{~W}$ ), SEY (Mahe Island, Seychelles, 4.67 S, 55.17 E) and WIS (Sede Boker, Israel, $31.13 \mathrm{~N}, 34.88 \mathrm{E}$ ). The departure statistics before and after the MOPITT inversion appear in Table 2. The posterior significantly improves the fit to the individual observations at all stations with respect to the prior. Over the seven-year period, the root mean square departures are reduced by up to $25 \%$, while the bias is also significantly reduced.

\section{Conclusions}

This paper represents a first step in extending the variational inversion system of Chevallier et al. (2005) to reactive gases. Compared to the 2005 paper, a simplified chemistry mod-
Table 2. Statistics of the model-minus-observation departures, in ppb, at five stations of the NOAA ESRL network over the 20002006 period covered by MOPITT. The model uses either the prior or the posterior $\mathrm{CO}$ emissions. The flask data have not been used in the inversion system.

\begin{tabular}{lrrrr}
\hline Station & $\begin{array}{r}\text { Prior } \\
\text { Bias }\end{array}$ & $\begin{array}{r}\text { Posterior } \\
\text { Bias }\end{array}$ & $\begin{array}{r}\text { Prior } \\
\text { RMS }\end{array}$ & $\begin{array}{r}\text { Posterior } \\
\text { RMS }\end{array}$ \\
\hline ASC & -5 & 0 & 16 & 12 \\
ASK & -21 & -15 & 24 & 19 \\
IZO & -23 & -18 & 27 & 23 \\
SEY & -10 & -5 & 14 & 14 \\
WIS & -29 & -23 & 36 & 31 \\
\hline
\end{tabular}

ule for hydrocarbon oxidation chain has been developed, the M1QN3 minimizer has been implemented, and the system has been interfaced to the individual MOPITT data, including their averaging kernels. The MOPITT archive over the 2000-2006 period has been processed and the results analysed for the African continent. The error budget indicates that the MOPITT data should in principle reduce the uncertainty about the African emissions significantly, even at the grid point level. This is confirmed on real data by the comparison of the prior (i.e. before the MOPITT-based inversion) and of the posterior (i.e. after the MOPITT-based inversion) model simulation at five independent stations. It will be interesting to extend the validation to aircraft measurements, like those of the MOZAIC program (Measurements of Ozone, Water Vapour, Carbon Monoxide and Nitrogen Oxides by In-Service Airbus Aircraft, Marenco et al. (1998)). The results for the rest of the globe are still being analysed. Their quality influences the present results over Africa to some extent, since they implicitly provide boundary conditions for the regional inversion problem.

The CO budget in Africa is dominated by fires. Fresh tropical biomass burning plumes are usually confined in the boundary layer (e.g., Labonne et al., 2007) and may leave the African continent at low elevation (Garstang et al., 1996). By the time the plumes reach the free troposphere, they may be well depleted in CO (Mauzerall et al., 1998). As a result, biomass burning induces large gradients in the $\mathrm{CO}$ vertical profiles over tropical lands (e.g., Yokelson et al., 2003, 2007). Depending on the thermal contrast at the surface, the MOPITT instrument has some sensitivity to lower tropospheric CO (Deeter et al., 2007), but cannot capture these steep gradients. Further, the early overpass of the MOPITT spacecraft during daytime (10:30 LT) does not favour the observation of the boundary layer, that develops mostly in the afternoon. Therefore, MOPITT provides only coarse spatial information about the $\mathrm{CO}$ emissions.

The errors of the prior emissions have been empirically assigned. The inversion results would clearly benefit from a rigorous investigation of the statistical characteristics of 
the emission inventory errors (e.g., Chevallier et al., 2006). However, such a task will be complicated by the high variability of the $\mathrm{CO}$ emissions in space and in time, that makes the error distributions diverge from normality.

A major advantage of the new system relies on its flexibility to accommodate new observations related to the hydrocarbon oxidation chain: $\mathrm{CO}, \mathrm{CH}_{4}, \mathrm{HCHO}$ and $\mathrm{MCF}$ observations can be analysed in synergy, with the observations about any one of the species helping constrain the other species. For the inversion of $\mathrm{CO}$ emissions, the major improvement is expected from the contribution of $\mathrm{HCHO}$ retrievals, like those of Global Ozone Monitoring Experiment (GOME) or from the SCanning Imaging Absorption SpectroMeter for Atmospheric CHartographY (SCIAMACHY) (e.g., De Smedt et al., 2008). Additionally, introducing other CO retrieval products together with MOPITT in the system, like those from the Infrared Atmospheric Sounding Interferometer (IASI) (Turquety et al., 2004), should reduce the impact of possible biases in individual products.

Acknowledgements. MOPITT data were obtained from the NASA Langley Research Center Atmospheric Sciences Data Center. We also acknowledge the NOAA/ESRL and the AGAGE Science Team for providing the in situ measurements. Authors wish to thank F. Marabelle (LSCE) for computer support, C. Carouge for her installation of version 4 of LMDZ and two anonymous reviewers for their constructive comments. The study was co-funded by EU FP6 project CARBOAFRICA, by the French space agency CNES and by LEFE/ASSIM project SACAS. The works of I. Pison and S. Szopa are supported respectively by grants of the FP6 EU-projects HYMN and GEOmon.

Edited by: J. Kesselmeier

\section{References}

Arellano Jr., A. F., Kasibhatla, P. S., Giglio, L., van der Werf, G. R., and Randerson, J. T.: Top-down estimates of global CO sources using MOPITT measurements, Geophys. Res. Lett., 31, L01104, doi:10.1029/2003GL018609, 2004.

Arellano Jr., A. F., Kasibhatla, P. S., Giglio, L., van der Werf, G. R., Randerson, J. T., and Collatz, G. J.: Timedependent inversion estimates of global biomass-burning $\mathrm{CO}$ emissions using Measurement of Pollution in the Troposphere (MOPITT) measurements, J. Geophys. Res., 111, D09303, doi:10.1029/2005JD006613, 2006.

Bergamaschi, P., Frankenberg, C., Meirink, J. F., et al.: Satellite chartography of atmospheric methane from SCIAMACHY on board ENVISAT: 2. Evaluation based on inverse model simulations, J. Geophys. Res., 112, D02304, doi:10.1029/2006JD007268, 2007.

Boschetti, L., Eva, H. D., Brivio, P. A., and Grégoire, J. M.: Lessons to be learned from the comparison of three satellite-derived biomass burning products, Geophys. Res. Lett., 31, L21501, doi:10.1029/2004GL021229, 2004.

Bousquet, P., Hauglustaine, D. A., Peylin, P., Carouge, C., and Ciais, P.: Two decades of $\mathrm{OH}$ variability as inferred by an in- version of atmospheric transport and chemistry of methyl chloroform, Atmos. Chem. Phys., 5, 2635-2656, 2005, http://www.atmos-chem-phys.net/5/2635/2005/.

Chédin, A., Serrar, S., Scott, N. A., Crevoisier, C., and Armante, R.: First global measurement of midtropospheric $\mathrm{CO}_{2}$ from NOAA polar satellites: Tropical zone, J. Geophys. Res., 108(D18), 4581, doi:10.1029/2003JD003439, 2003.

Chevallier, F., Fisher, M., Peylin, P., Serrar, S., Bousquet, P., Bréon, F.-M., Chédin, A., and Ciais, P.: Inferring $\mathrm{CO}_{2}$ sources and sinks from satellite observations: method and application to TOVS data, J. Geophys. Res., 110, D24309, doi:10.1029/2005JD006390, 2005.

Chevallier, F., Viovy, N., Reichstein, M., and Ciais, P.: On the assignment of prior errors in Bayesian inversions of $\mathrm{CO}_{2}$ surface fluxes, Geophys. Res. Lett., 33, L13802, doi:10.1029/2006GL026496, 2006.

Chevallier, F., Bréon, F.-M., and Rayner, P. J.: Contribution of the Orbiting Carbon Observatory to the estimation of $\mathrm{CO}_{2}$ sources and sinks: Theoretical study in a variational data assimilation framework, J. Geophys. Res., 112, D09307, doi:10.1029/2006JD007375, 2007.

Ciais, P., Piao, S.-L., Cadule, P., Friedlingstein, P., and Chédin, A.: Variability and recent trends in the African carbon balance, Biogeosci. Discuss., 5, 3497-3532, 2008.

De Smedt, I., Müller, J.-F., Stavrakou, T., van der A, R., Eskes, H., and Van Roozendael, M.: Twelve years of global observations of formaldehyde in the troposphere using GOME and SCIAMACHY sensors, Atmos. Chem. Phys., 8, 4947-4963, 2008, http://www.atmos-chem-phys.net/8/4947/2008/.

Deeter, M. N., Emmons, L. K., Francis, G. L., et al.: Operational carbon monoxide retrieval algorithm and selected results for the MOPITT instrument, J. Geophys. Res., 108(D14), 4399, doi:10.1029/2002JD003186, 2003.

Deeter, M. N., Emmons, L. K., Edwards, D. P., Gille, J. C., and Drummond, J. R.: Vertical resolution and information content of CO profiles retrieved by MOPITT, Geophys. Res. Lett., 31, L15112, doi:10.1029/2004GL020235, 2004.

Deeter, M. N., D. P. Edwards, J. C. Gille, and J. R. Drummond: Sensitivity of MOPITT observations to carbon monoxide in the lower troposphere, J. Geophys. Res., 112, D24306, doi:10.1029/2007JD008929, 2007.

Emmons, L. K., Deeter, M. N., Gille, J. C., et al.: Validation of Measurements of Pollution in the Troposphere (MOPITT) CO retrievals with aircraft in situ profiles, J. Geophys. Res., 109, D03309, doi:10.1029/2003JD004101, 2004.

Emmons, L. K., Edwards, D. P., Deeter, M. N., Gille, J. C., Campos, T., Nédélec, P., Novelli, P., and Sachse, G.: Measurements of Pollution In The Troposphere (MOPITT) validation through 2006, Atmos. Chem. Phys. Discuss., 8, 18091-18109, 2008, http://www.atmos-chem-phys-discuss.net/8/18091/2008/.

Folberth, G. A., Hauglustaine, D. A., Lathière, J., and Brocheto, F.: Interactive chemistry in the Laboratoire de Météorologie Dynamique general circulation model: model description and impact analysis of biogenic hydrocarbons on tropospheric chemistry, Atmos. Chem. Phys., 6, 2273-2319, 2006, http://www.atmos-chem-phys.net/6/2273/2006/.

Garstang, M., Scala, J., Greco, S., et al.: Trace Gas Exchanges and Convective Transports Over the Amazonian Rain Forest, J. Geophys. Res., 93(D2), 1528-1550, 1996. 
Gilbert, J. C. and Lemaréchal, C.: Some numerical experiments with variable-storage quasi-Newton algorithms, Math. Program., 45, 407-435, 1989.

Hauglustaine, D. A., Hourdin, F., Jourdain, L., Filiberti, M.A., Walters, S.,Lamarque, J.-F., and Holland, E. A.: Interactive chemistry in the Laboratoire de Météorologie Dynamique general circulation model: Description and background tropospheric chemistry evaluation, J. Geophys. Res., 109, D04314, doi:10.1029/2003JD003957, 2004.

Hourdin, F., Talagrand, O., and Idelkadi, A.: Eulerian backtracking of atmospheric tracers. II: Numerical aspects, Q. J. Roy. Meteor. Soc., 132, 585-603, 2006.

Hourdin, F., Musat, I., Bony, S., et al.: The LMDZ4 general circulation model: climate performance and sensitivity to parametrized physics with emphasis on tropical convection, Clim. Dynam., 27, 787-813, 2007.

Labonne, M., Bréon, F.-M., and Chevallier, F.: Injection height of biomass burning aerosols as seen from a spaceborne lidar, Geophys. Res. Lett., 34, L11806, doi:10.1029/2007GL029311, 2007.

Le Dimet, F.-X. and Talagrand, O.: Variational algorithms for analysis and assimilation of meteorological observations: theoretical aspects, Tellus, 38A, 97-110, 1986.

Marenco, A., Thouret, V., Nédélec, P., et al.: Measurement of ozone and water vapor by Airbus in-service aircraft: The MOZAIC airborne program, An overview, J. Geophys. Res., 103(D19), 25631-25642, 1998.

Mauzerall, D. L., J. A. Logan, D. J. Jacob, B. E. Anderson, D. R. Blake, Bradshaw,J. D., Heikes, B., Sachse, G. W., Singh, H., and Talbot, B.: Photochemistry in biomass burning plumes and implications for tropospheric ozone over the tropical South Atlantic, J. Geophys. Res., 103(D7), 8401-8423, 1998.

Montzka, S. A., Spivakovsky, C. M., Butler, J. H., Elkins, J. W., Lock, L. T., and Mondeel, D. J.: New observational constraints for atmospheric hydroxyl on global and hemispheric scales, Science, 288, 500-503, 2000.

Olivier, J. G. J. and Berdowski, J. J. M.: Global emissions sources and sinks, in: The Climate System, edited by: Berdowski, J., Guicherit, R. and Heij, B. J., A. A. Balkema Publishers/Swets \& Zeitlinger Publishers, Lisse, The Netherlands, ISBN-90-5809255-0, 33-78, 2001.

Pétron, G., Granier, C., Khattatov, B., Yudin, V., Lamarque, J.-F., Emmons, L., Gille, J., and Edwards, D. P.: Monthly CO surface sources inventory based on the 20002001 MOPITT satellite data, Geophys. Res. Lett., 31, L21107, doi:10.1029/2004GL020560, 2004.
Pison, I., Bousquet, P., Chevallier, F., Szopa, S., and Hauglustaine, D. A.: Multi-species inversion of $\mathrm{CH}_{4}, \mathrm{CO}$ and $\mathrm{H}_{2}$ emissions from surface measurements, Atmos. Chem. Phys. Discuss., 8, 20687-20722, 2008, http://www.atmos-chem-phys-discuss.net/8/20687/2008/.

Prinn, R. G., Weiss, R. F., Miller, B. R., Huang, J., Alyea, F. N., Cunnold, D. M., Fraser, P. J., Hartley, D. E., and Simmonds, P. G.: Atmospheric Trends and Lifetime of $\mathrm{CH}_{3} \mathrm{CCl}_{3}$ and Global OH Concentrations, Science, 269(5221), 187-192, 1995.

Prinn, R. G., Weiss, R. F., Fraser, P. J., et al.: A history of chemically and radiatively important trace gases in air deduced from ALE/GAGE/AGAGE, J. Geophys. Res., 103, 17751-17790, 2000.

Rodgers, C. D.: Inverse methods for atmospheric sounding: theory and practice, World Scientific, Series on Atmospheric, Oceanic and Planetary Physics, 2, 238 pp., 2000.

Tucker, C. J.: Red and Photographic Infrared Linear Combinations for Monitoring Vegetation, Remote Sens. Environ., 8, 127-150, 1979.

Turner, D. S.: The effect of increasing $\mathrm{CO}_{2}$ amounts on TOVS longwave sounding channels, J. Appl. Meteor., 32, 1760-1765, 1993

Turquety, S., Hadji-Lazaro, J., Clerbaux, C., Hauglustaine, D. A., Clough, S. A., Cassé, V., Schlüssel, P., and Mégie, G.: Operational trace gas retrieval algorithm for the Infrared Atmospheric Sounding Interferometer, J. Geophys. Res., 109, D21301, doi:10.1029/2004JD004821, 2004.

Van der Werf, G. R., Randerson, J. T., Giglio, L., Collatz, G. J., and Kasibhatla, P. S.: Interannual variability in global biomass burning emission from 1997 to 2004, Atmos. Chem. Phys., 6, 3423-3441, 2006,

http://www.atmos-chem-phys.net/6/3423/2006/.

Yokelson R. J., Bertschi, I. T., Christian, T. J., Hobbs, P. V., Ward, D. E., and Hao, W. M.: Trace gas measurements in nascent, aged, and cloud-processed smoke from African savanna fires by airborne Fourier transform infrared spectroscopy (AFTIR), J. Geophys. Res., 108 (D13), 8478, doi:10.1029/2002JD002322, 2003.

Yokelson, R. J., Karl, T., Artaxo, P., Blake, D. R., Christian, T. J., Griffith, D. W. T., Guenther, A., and Hao, W. M.: The Tropical Forest and Fire Emissions Experiment: overview and airborne fire emission factor measurements, Atmos. Chem. Phys., 7, 5175-5196, 2007, http://www.atmoschem-phys.net/7/5175/2007/. 